\title{
Ambulatory blood pressure monitoring and subclinical inflammation in children with chronic kidney disease
}

\author{
Piotr Skrzypczyk', Michał Szyszka', Anna Ofiara², Beata Leszczyńska', Dominika Adamczuk', \\ Maria Daniel', Małgorzata Pańczyk-Tomaszewska' \\ 'Department of Pediatrics and Nephrology, Medical University of Warsaw, Warsaw, Poland \\ ${ }^{2}$ Student Scientific Group at the Department of Pediatrics and Nephrology, Medical University of Warsaw, Warsaw, Poland
}

\begin{abstract}
Background. Children with chronic kidney disease (CKD) are characterized by increased risk of hypertension and chronic low-grade inflammation. The aim of the study was the analysis of relation between parameters of ambulatory blood pressure monitoring (ABPM) and subclinical inflammation in children with CKD.

Material and methods. Study group included 27 paediatric patients (age $14.23 \pm 3.57$ years) with CKD stage 2-5; 18 children with previously recognized hypertension. In all patients we evaluated ABPM, office blood pressure, complete blood count and selected clinical and biochemical parameters.

Results. In the study group, GFR was from 7.05 to 86.73 , mean $40.88 \pm 25.82 \mathrm{~mL} / \mathrm{min} / 1.73 \mathrm{~m}^{2}$. All 9 children without hypertension had normal blood pressure in ABPM, but ABPM detected poor blood pressure control in 7 among 18 (38.9\%) children with previously recognized and treated hypertension. Abnormal circadian blood pressure profile was found in $12(44.4 \%)$ children: $9 / 18$ (50.0\%) with hypertension and 3/9 (33.3\%) with normal BP. Systolic, diastolic, mean blood pressure and diastolic blood pressure load correlated with neutrophil count, neutrophilto-lymphocyte ratio and platelet-to-lymphocyte ratio $(\mathrm{r}=0.39-0.49, \mathrm{p}=0.010-0.044)$; diastolic and mean blood pressure and diastolic blood pressure load with parathormone $(\mathrm{r}=0.48-0.57, \mathrm{p}=0.005-0.023)$; diastolic blood pressure load with phosphate and calcium-phosphorus product $(r=0.44-0.47, \mathrm{p}=0.021-0.030)$; diastolic blood pressure dipping with phosphate $(\mathrm{r}=-0.43, \mathrm{p}=0.034)$.

Conclusions. 1. Ambulatory blood pressure monitoring should be used in children with chronic kidney disease on a regular basis, especially in those with arterial hypertension. 2 . Blood pressure in children with chronic kidney disease may be related to degree of subclinical inflammation.

Key words: children; chronic kidney disease; hypertension; ambulatory blood pressure monitoring; inflammation

Arterial Hypertens. 2019, vol. 23, no. 1, pages: 14-21

DOI: $10.5603 /$ AH.a2019.0003
\end{abstract}

Address for correspondence: Piotr Skrzypczyk

Department of Pediatrics and Nephrology, Medical University of Warsaw

ul. Żwirki i Wigury 63A, 02-091 Warsaw, Poland, tel: (+48) 502507 822, fax: (+48) 223179954

e-mail: pskrzypczyk@wum.edu.pl

VM Copyright $(2019$ Via Medica, ISSN 2449-6170 


\section{Introduction}

Cardiovascular disease (CVD) is a leading cause of mortality in children with chronic kidney disease (CKD). The burden of CVD in children with CKD can be explained by accumulation of both traditional (hypertension, dyslipidaemia, obesity) and non-traditional, referred to as uraemia-related, risk factors (anaemia, albuminuria, abnormal mineral metabolism, overhydration, and subclinical inflammation) [1].

Twenty-four-hour ambulatory blood pressure monitoring $(\mathrm{ABPM})$ was found to be superior to casual (office) blood pressure measurement in detection of abnormal blood pressure. In many studies in adult and paediatric populations ABPM parameters showed better correlation with target organ damage compared to office measurements. High blood pressure variability, disturbed circadian blood pressure rhythm, and increased pulse pressure were found to be additional risk factors for the development of target organ damage [2]. Also based on ABPM data, the ambulatory arterial stiffness index (AASI) was proposed as a marker of arterial compliance [3].

The variety of factors contribute to chronic inflammatory status in patients with CKD, including increased production and decreased clearance of proinflammatory cytokines, oxidative stress, acidosis, infections, including those related to dialysis access, altered metabolism of adipose tissue, and intestinal dysbiosis. The inflammation was found to correlate negatively with the glomerular filtration rate (GFR) in CKD and culminates in dialysis patients, where extracorporeal and bioincompatible factors (dialysis water, microbiological quality of the dialysate, dialyzer membranes) in the dialysis circuit play an additional role [4].

Neutrophil count, neutrophil-to-lymphocyte ratio, platelet-to-lymphocyte ratio, and mean platelet volume are easy accessible, complete blood count (CBC)-derived inflammatory markers that were found to correlate with blood pressure and target organ damage in adult patients with cardiovascular diseases [5-9].

There are only few data on relation between hypertension, cardiovascular risk and inflammation in patients with chronic kidney disease $[6,7,10]$. Preliminary data suggest positive relation between degree of subclinical inflammation and cardiovascular burden in these patients, as concentration of highly-sensitive CRP (hsCRP) was found to correlate positively with both systolic and diastolic blood pressure [10].

To the best of our knowledge there are no data on relation between blood pressure measured by ABPM and $\mathrm{CBC}$-derived inflammatory markers in children with CKD.

Thus, the aim of our study was to analyse the relation between results of ambulatory blood pressure monitoring and subclinical inflammation in children with CKD.

\section{Material and methods}

We analysed retrospectively clinical data of 27 children and adolescents with chronic kidney disease stages G2-G5 according to KDIGO (Kidney Disease Improving Global Outcome) classification [11] treated in one tertiary centre of paediatric nephrology. Children with coexisting congenital or acquired heart defects and children with acute infections or other evident sources of inflammation were excluded from the study.

The following clinical data were collected from all CKD patients: age [years]; gender, aetiology of CKD according to ESPN/ERA-EDTA (European Society for Paediatric Nephrology/European Renal Association-European Dialysis and Transplantation Association) Registry (www.espn-reg.org/index.jsp); CKD stage according to KDIGO classification [11] based on estimated glomerular filtration rate (eGFR) derived by the modified Schwartz formula [12]; body mass $[\mathrm{kg}]$; height $[\mathrm{m}]$ and body mass index (BMI) $\left[\mathrm{kg} / \mathrm{m}^{2}\right]$ (Z-scores were calculated from national normative data [13]); hypertension diagnosed according to Polish Society of Hypertension guidelines [14]; and medications that might affect cardiovascular system. Overweight and obesity were defined according to World Health Organization definitions as BMI Z-score values $>1$ and $>2$, respectively.

Peripheral blood pressure was measured using oscillometric device (Welch Allyn VSM Patient Monitor 300, Welch Allyn, USA). Obtained values were expressed as $[\mathrm{mm} \mathrm{Hg}]$ and were compared with normative values [15] and expressed as Z-score.

Twenty-four-hour blood pressure measurement was performed using a SUNTECH OSCAR 2 device (SunTech Medical, Inc., Morrisville, NC, USA) and interpreted according to the American Heart Association (AHA) guidelines. Monitors were programmed to measure blood pressure every 15 minutes from $6 \mathrm{AM}$ to $10 \mathrm{PM}$ and every 30 minutes from 10 PM to 6 AM. Periods of nighttime rest and daytime activity were determined individually by providing data in a diary. Following parameters were evaluated based on ABPM: systolic, diastolic, and mean arterial pressure (SBP, DBP, MAP) during 24 hours [mm Hg]; pulse pres- 
sure (PP) during 24 hours [mm Hg]; systolic and diastolic blood pressure load during 24 hours [\%]; nocturnal blood pressure dip (\%); blood pressure variability; and AASI. Pulse pressure was calculated as the difference between mean SBP and DBP during 24 hours, blood pressure load as a percentage of measurements $\geq 95^{\text {th }}$ percentile during 24 hours and increased load was defined as $>25 \%$ [2]. AASI was calculated as 1 minus correlation coefficient between diastolic and systolic blood pressure values over 24 hours in ABPM [3]. Nocturnal systolic and diastolic blood pressure dip (SBP DIP, DBP DIP, respectively) was calculated as the difference between daytime pressure and nighttime pressure expressed as a percentage of the day value. Disturbed circadian blood pressure rhythm was defined as nocturnal systolic or diastolic blood pressure dip less than $10 \%$. Blood pressure variability was calculated as standard deviation (SD) from the mean of all systolic or diastolic blood pressure values over 24 hours (SD SBP/24h, SD DBP/24h) [2].

In all the studied children peripheral automated complete blood count was performed using Coulter LH 780 hematologic analyser (Beckman Coulter Inc., Brea, CA, USA). Following parameters of $\mathrm{CBC}$ were evaluated: haemoglobin concentration $(\mathrm{Hb})[\mathrm{g} / \mathrm{dL}]$, number of neutrophils (NEU) $[$ ths $/ \mu \mathrm{L}]$, number of lymphocytes (LYM) [ths $/ \mu \mathrm{L}]$, number of platelets (PLT) $[$ ths $/ \mu \mathrm{L}]$, mean platelet volume (MPV) [fL], neutrophil-to-lymphocyte ratio (NLR), and platelet-to-lymphocyte ratio (PLR). In addition, serum concentrations of the following biochemical parameters were assessed: creatinine $[\mathrm{mg} / \mathrm{dL}]$, urea $[\mathrm{mg} / \mathrm{dL}]$, uric acid $[\mathrm{mg} / \mathrm{dL}]$, total, low-density lipoprotein and high-density lipoprotein cholesterol $[\mathrm{mg} / \mathrm{dL}]$, calcium $[\mathrm{mg} / \mathrm{dL}]$, inorganic phosphate $[\mathrm{mg} / \mathrm{dL}]$, alkaline phosphatase $[\mathrm{IU} / \mathrm{mL}]$, intact parathormone $[\mathrm{pg} / \mathrm{mL}], 25$-hydroxy-vitamin D $(25(\mathrm{OH}) \mathrm{D})[\mathrm{ng} / \mathrm{mL}]$. iPTH was measured using a solid-phase, two-site chemiluminescent enzyme-labelled immunometric assay, IMMULITE 2000, Siemens. 25(OH)D was assessed using a one-step delayed chemiluminescent microparticle immunoassay, ARCHITECT i1000SR, Abbott. The remaining biochemical variables were measured using VITROS 5600 Integrated System, Ortho Clinical Diagnostics. Patients' biochemical data were compared with KDIGO recommended values (haemoglobin) [16], and European Paediatric Dialysis Working Group (EPDWG) guidelines (calcium-phosphorus metabolism) [17]. According to Polish recommendations vitamin $\mathrm{D}$ concentrations were defined as: severe deficiency $(0-10 \mathrm{ng} / \mathrm{mL})$, deficiency (> 10-20 ng/mL), suboptimal (> 20-30 $\mathrm{ng} / \mathrm{mL}$ ), optimal (> 30-50 $\mathrm{ng} / \mathrm{mL})$, high (> 50-100 $\mathrm{ng} / \mathrm{ml})$, and toxic $(>100 \mathrm{ng} / \mathrm{mL}$ ) levels [18]. Normal concentrations of calcium $(8.8-10.7 \mathrm{mg} / \mathrm{dL}$ ), phosphate $(2.8-5.6 \mathrm{mg} / \mathrm{dL})$, alkaline phosphatase (45-515 IU/L), and parathormone $(12-95 \mathrm{pg} / \mathrm{mL})$ were taken from normative values in accordance with producer's recommendations. Hypoalbuminemia was defined as serum albumin concentration $<3.5 \mathrm{~g} / \mathrm{dL}$, hyperuricemia as uric acid $>6.0 \mathrm{mg} / \mathrm{dL}$, hypercholesterolemia as cholesterol $\geq 200 \mathrm{mg} / \mathrm{dL}$, and hypertriglyceridemia as triglyceride $\geq 100 \mathrm{mg} / \mathrm{dL}$ (children aged $0-9$ years) or $\geq 130 \mathrm{mg} / \mathrm{dL}$ (children aged 10-19 years).

Additionally, low-sensitivity C-reactive protein was measured in the studied children using VITROS 5600 Integrated System and was within normal limits $(<1.0 \mathrm{mg} / \mathrm{dL})$ in all the participants.

All procedures were performed in accordance with the Declaration of Helsinki on the treatment of human subjects. Due to retrospective nature of the study formal informed consent was not required.

\section{Statistical analysis}

Statistical elaboration was performed using Dell Statistica 13.0 PL software (Dell Inc., AlisoViejo, CA, USA). Variables were presented as the mean \pm standard deviation (SD). Normality of data distribution was tested using the Shapiro-Wilk test. Correlations between parametric and non-parametric variables were evaluated using the Pearson and the Spearman rank correlation, respectively. A p-value $<0.05$ was considered statistically significant.

\section{Results}

The clinical characteristics of children included in the study are presented in Table I. The most common cause of CKD were congenital anomalies of the kidney and the urinary tract (CAKUT), followed by glomerular disorders (Henoch-Schoenlein nephropathy in 2 , IgA nephropathy in 1, membrano-proliferative nephropathy in 1 and focal and segmental glomerulosclerosis in 1). Among five patients with CKD stage 5 , three received renal replacement therapy (RRT). One child was overweight, 2 children were obese and 2 were underweight (with BMI Z-score below -2 ). Two thirds of CKD children had hypertension, among which most patients received at least 2 antihypertensive medications. Dihydropyridine calcium channel blockers (CCBs) were most frequently used medications. Two children without hypertension received angiotensin converting enzyme inhibitors (ACEIs) as a renoprotective treatment; the same two 
Table I. Clinical characteristics of children with chronic kidney disease

\begin{tabular}{|c|c|}
\hline Analysed parameter & CKD patients \\
\hline Number of patients (n) & 27 \\
\hline Age [years] & $\begin{array}{c}14.23 \pm 3.57 \\
\text { (from } 4.83 \text { to } 17.92 \text { ) }\end{array}$ \\
\hline Gender (males / females) & $16 / 11$ \\
\hline $\begin{array}{l}\text { CKD aetiology [n (\%)] } \\
\text { CAKUT } \\
\text { Glomerulonephritis } \\
\text { Hereditary nephropathy } \\
\text { Toxic/ischaemic kidney injury } \\
\text { Cystic kidney disease } \\
\text { Haemolytic-uremic syndrome }\end{array}$ & $\begin{array}{l}10(37 \%) \\
5(19 \%) \\
2(7 \%) \\
3(11 \%) \\
4(15 \%) \\
3(11 \%)\end{array}$ \\
\hline $\begin{array}{l}\text { CKD stage }[n(\%)] \\
2 \\
3 \\
4 \\
5\end{array}$ & $\begin{array}{l}8(30 \%) \\
7(26 \%) \\
7(26 \%) \\
5(18 \%)\end{array}$ \\
\hline $\begin{array}{l}\text { Renal replacement therapy [n (\%)] } \\
\text { Automated peritoneal dialysis } \\
\text { Peritoneal dialysis }\end{array}$ & $\begin{array}{c}3(11 \%) \\
2 \\
1\end{array}$ \\
\hline BMI Z-score & $-0.21 \pm 1.34$ \\
\hline Hypertension [n (\%)] & $18(67 \%)$ \\
\hline $\begin{array}{l}\text { Antihypertensive medications [n (\%)] } \\
\text { Calcium channel blockers } \\
\text { Angiotensin converting enzyme inhibitors } \\
\text { Beta-blockers } \\
\text { Alpha-blockers } \\
\text { Angiotensin receptor blockers } \\
\text { Hydrochlorothiazide }\end{array}$ & $\begin{array}{c}16(59 \%) \\
12(44 \%) \\
5(19 \%) \\
3(11 \%) \\
1(4 \%) \\
1(4 \%)\end{array}$ \\
\hline $\begin{array}{l}\text { Number of antihypertensive medications in } \\
\text { children with hypertension [n }(\%)] \\
1 \\
2 \\
3\end{array}$ & $\begin{array}{c}1.83 \pm 0.62 \\
5(28 \%) \\
11(61 \%) \\
2(11 \%)\end{array}$ \\
\hline Cholecalciferol [n (\%)] & $18(67 \%)$ \\
\hline Alphacalcidol [n (\%)] & $11(41 \%)$ \\
\hline $\mathrm{CaCO}_{3}[\mathrm{n}(\%)]$ & $12(44 \%)$ \\
\hline $\mathrm{NaHCO}_{3}[\mathrm{n}(\%)]$ & $6(22 \%)$ \\
\hline Erythropoiesis-stimulating agents [n (\%)] & $6(22 \%)$ \\
\hline $\begin{array}{l}\text { Recombinant human growth hormone [n } \\
(\%)]\end{array}$ & $3(11 \%)$ \\
\hline Prednisone [n (\%)] & $3(11 \%)$ \\
\hline
\end{tabular}

patients received doxazosin as a treatment of urinary bladder dysfunction. Three children with glomerular kidney diseases were treated with prednisone.

Blood pressure measurements are presented in Table II. All 9 children without hypertension had normal blood pressure in ABPM, but ABPM detected poor blood pressure control in 7 among 18 $(38.9 \%)$ children with previously recognized and
Table II. Blood pressure measurements in the studied children

\begin{tabular}{|c|c|}
\hline \multicolumn{2}{|l|}{ Office blood pressure } \\
\hline $\begin{array}{l}\text { Systolic blood pressure [mm Hg] } \\
\text { Systolic blood pressure Z-score }\end{array}$ & $\begin{array}{c}117.24 \pm 13.90 \\
0.79 \pm 1.31\end{array}$ \\
\hline $\begin{array}{l}\text { Diastolic blood pressure [mm Hg] } \\
\text { Diastolic blood pressure Z-score }\end{array}$ & $\begin{array}{c}73.67 \pm 12.43 \\
0.87 \pm 1.03\end{array}$ \\
\hline \multicolumn{2}{|l|}{ 24-hour ambulatory blood pressure monitoring } \\
\hline Systolic blood pressure during $24 \mathrm{~h} \mathrm{[mm} \mathrm{Hg}$ ] & $122.19 \pm 9.66$ \\
\hline Diastolic blood pressure during $24 \mathrm{~h}$ [mm Hg] & $70.63 \pm 10.09$ \\
\hline Mean blood pressure during $24 \mathrm{~h}$ [mm Hg] & $87.85 \pm 9.50$ \\
\hline Pulse pressure during $24 \mathrm{~h}$ [mm Hg] & $51.41 \pm 7.06$ \\
\hline SBP load during $24 \mathrm{~h}(\%)$ & $34.07 \pm 27.87$ \\
\hline DBP load during $24 \mathrm{~h}(\%)$ & $25.70 \pm 29.89$ \\
\hline SBP variability & $11.50 \pm 2.10$ \\
\hline DBP variability & $10.25 \pm 1.94$ \\
\hline SBP dipping (\%) & $10.27 \pm 4.28$ \\
\hline DBP dipping $(\%)$ & $15.91 \pm 7.69$ \\
\hline Ambulatory arterial stiffness index & $0.32 \pm 0.10$ \\
\hline
\end{tabular}

treated hypertension. Abnormal circadian profile of blood pressure was found in $12(44.4 \%)$ children: $3 / 9(33.3 \%)$ with normal BP and 9/18 (50.0\%) with hypertension.

Complete blood count, CBC-derived inflammatory markers, and biochemical parameters are presented in Table III. Anaemia was found in $5(19 \%)$ children, hyperuricemia in 11 (41\%), hypercholesterolemia in $2(7 \%)$, and hypertriglyceridemia in 6 $(22 \%)$ patients. Serum calcium was within normal limits in all studied children, whereas serum phosphate was increased in $4(15 \%)$ patients. Calciumphosphorus product was elevated in $2(7 \%)$ patients and was normal in the remaining children. Vitamin $\mathrm{D}$ deficiency was found in $9(33 \%)$ children. Serum iPTH was lowered in $2(7 \%)$, and elevated in 9 (33\%) patients, and alkaline phosphatase was normal in all the patients.

Correlations of ABPM parameters with inflammatory markers and parathormone are presented in Table IV. Systolic, diastolic and mean blood pressure, as well as diastolic blood pressure load during 24 hours correlated positively with $\mathrm{CBC}$-derived inflammatory markers: neutrophil count, neutrophilto-lymphocyte ratio, and platelet-to-lymphocyte ratio. Diastolic and mean blood pressure and diastolic blood pressure load also correlated positively with level of parathyroid hormone. Inflammatory markers did not correlate with age in the study group. In addition, diastolic blood pressure load during 24 hours correlated positively with phosphate $(r=0.47$, 
Table III. Biochemical parameters in the study group

\begin{tabular}{|l|c|}
\hline Parameter & Study group \\
\hline Haemoglobin [g/dL] & $12.71 \pm 1.96$ \\
\hline Neutrophils [ths/ $\mu \mathrm{L}]$ & $4.36 \pm 2.46$ \\
\hline Lymphocytes [ths/ $\mu \mathrm{L}]$ & $2.27 \pm 0.81$ \\
\hline Platelets [ths/ $\mu \mathrm{L}]$ & $233.33 \pm 59.11$ \\
\hline NLR & $2.48 \pm 2.96$ \\
\hline PLR & $118.61 \pm 74.24$ \\
\hline Mean platelet volume [fL] & $9.06 \pm 1.69$ \\
\hline GFR [mL/min/1.73m $\left.{ }^{2}\right]$ & $40.88 \pm 25.82$ \\
\hline Urea [mg/dL] & (from 7.05 to 86.73) \\
\hline Uric acid [mg/dL] & $75.74 \pm 45.54$ \\
\hline Total cholesterol [mg/dL] & $7.05 \pm 2.37$ \\
\hline Triglyceride [mg/dL] & $175.80 \pm 31.82$ \\
\hline Calcium [mg/dL] & $191.17 \pm 91.71$ \\
\hline Inorganic phosphate [mg/dL] & $9.89 \pm 0.51$ \\
\hline Calcium-phosphorus product [mg $\left./{ }^{2} / \mathrm{dL}^{2}\right]$ & $4.95 \pm 0.85$ \\
\hline 25(OH)D [ng/mL] & $48.96 \pm 7.76$ \\
\hline Intact parathormone [pg/mL] & $19.43 \pm 8.17$ \\
\hline Alkaline phosphatase [U/L] & $146.23 \pm 170.14$ \\
\hline pH & $180.18 \pm 82.33$ \\
\hline HCO ${ }_{3}^{-}[\mathrm{mmol} / \mathrm{L}]$ & $7.39 \pm 0.04$ \\
\hline NLR - neutrophil-to-lymphocyte ratio; PLR - platelet-to-lymphocyte ratio; GFR - glomerular filtration \\
rate & \\
\hline
\end{tabular}

$\mathrm{p}=0.021)$ and calcium-phosphorus product $(\mathrm{r}=0.44$, $\mathrm{p}=0.030)$. We found also positive correlation of pulse pressure during 24 hours with haemoglobin $(\mathrm{r}=0.50, \mathrm{p}=0.008)$, and positive correlation of heart rate during 24 hours with platelet count $(\mathrm{r}=0.51, \mathrm{p}=0.007)$. We found also negative correlation of diastolic blood pressure dipping with phosphate $(r=-0.43, p=0.034)$. Ambulatory arte- rial stiffness index correlated significantly only with lymphocyte count $(\mathrm{r}=0.52, \mathrm{p}=0.019)$. We found no other significant correlations of AASI with clinical and biochemical parameters in the study group.

We also found positive correlations between office blood pressure measurements and inflammatory indicators: diastolic blood pressure expressed as both $[\mathrm{mm} \mathrm{Hg}]$ and Z-score correlated with neutrophil count $(\mathrm{r}=0.60, \mathrm{p}=0.004$ and $\mathrm{r}=0.59, \mathrm{p}=0.004)$ and with NLR $(\mathrm{r}=0.57, \mathrm{p}=0.006$ and $\mathrm{r}=0.61$, $\mathrm{p}=0.003)$.

In our study group, calcium correlated positively with lymphocyte and platelet count $(\mathrm{r}=0.41$, $\mathrm{p}=0.036$ and $\mathrm{r}=0.50, \mathrm{p}=0.009)$. No other significant correlations between inflammatory markers and parameters of calcium-phosphorus metabolism including vitamin D concentration were found.

\section{Discussion}

Analysis of blood pressure monitoring in our group of children with chronic kidney disease revealed poor control of previously recognized hypertension in more than two thirds of patients. According to American Heart Association guidelines, ABPM should be regularly used in children with CKD, also in those with normal blood pressure in office measurements [2]. Children with CKD are prone to develop nighttime hypertension and masked hypertension which cannot be detected in office measurements [19]. Though we have not found any patients with masked hypertension, ABPM enabled detection of poor control in many hypertensive children. It must be emphasized that masked hypertension is almost as strong predictor of left ventricular hypertrophy as office hypertension, which was proven both for children with primary hypertension [20] and

Table IV. Correlations of blood pressure parameters and age with inflammatory indicators and parathormone

\begin{tabular}{|l|c|c|c|c|}
\hline & NEU [1000/ $\mu \mathrm{L}]$ & NLR & PLR & iPTH [pg/mL] \\
\hline SBP 24h & $r=0.39$ & $r=0.40$ & $r=0.45$ & $r=0.25$ \\
[mm Hg] & $p=0.042$ & $p=0.040$ & $p=0.019$ & $p=0.255$ \\
\hline DBP 24h & $r=0.47$ & $r=0.42$ & $r=0.46$ & $r=0.53$ \\
[mm Hg] & $p=0.013$ & $p=0.029$ & $p=0.016$ & $p=0.010$ \\
\hline MAP 24h & $r=0.49$ & $r=0.44$ & $r=0.48$ & $p=0.48$ \\
[mm Hg] & $p=0.010$ & $p=0.021$ & $p=0.011$ & $r=0.57$ \\
\hline DBPL 24h & $r=0.47$ & $r=0.40$ & $r=0.39$ & $p=0.005$ \\
\hline [mm Hg] & $p=0.013$ & $p=0.041$ & $p=0.044$ & $r=0.03$ \\
\hline Age & $r=0.17$ & $r=0.10$ & $r=-0.08$ & $p=0.887$ \\
\hline [years] & $p=0.393$ & $p=0.612$ & $p=0.695$ & \\
\hline
\end{tabular}

NEU — neutrophil count; NLR — neutrophil-to-lymphocyte ratio; PLR — platelet-to-lymphocyte ratio; iPTH — intact parathormone; SBP 24h — systolic blood pressure during 24 hours; DBP $24 \mathrm{~h}$ - diastolic blood pressure during 24 hours; MAP $24 \mathrm{~h}$ - mean arterial pressure during 24 hours; DBPL $24 \mathrm{~h}$ — diastolic blood pressure load during 24 hours 
with hypertension in the course of CKD [21]. Our results highlight the need for regular ABPM evaluation in children with chronic kidney disease.

Abnormal circadian blood pressure profile was revealed in almost half of our patients. Our results are in accordance with results of other studies analysing ABPM results in children with CKD. Mitsnefes found abnormal systolic blood pressure dipping in $59 \%$ and abnormal diastolic dipping in $31 \%$ of children with chronic renal insufficiency [22]. It is hypothesized that disturbed circadian blood pressure profile in patients with kidney diseases might be caused by increased sympathetic activity due to stimulation by afferent renal fibres. More frequent target organ damage such as left ventricular hypertrophy was observed in children with disturbed circadian blood pressure profile [23]. Moreover, many studies showed that nocturnal hypertension is an independent risk factor for kidney function decline [24].

We have found significant positive correlations between blood pressure evaluated by ABPM and complete blood count-derived inflammatory markers: neutrophil count, neutrophil-to-lymphocyte ratio, and platelet-to-lymphocyte ratio. In addition, office diastolic blood pressure correlated with neutrophil count and NLR. Obviously, both blood pressure values and parameters of blood morphology are agedependent. Though, this relation is not distorted by age, as all these inflammatory indicators did not correlate with age in our cohort. Moreover, this relation was still present when office blood pressure was expressed as Z-score.

Neutrophils are the most abundant type of white blood cells and the first cells responding to inflammation, especially if it is caused by a bacterial infection or environmental exposure like burns. They release many cytokines that trigger and amplify inflammatory reactions. Neutrophil-to-lymphocyte ratio is an inexpensive, reproducible test and has shown up as a marker of systemic inflammatory response. Adult studies have shown that high NLR is associated with poor clinical outcomes in cardiac diseases [5]. While high neutrophil count reflects inflammation, low lymphocyte count reflects poor general health and physiological stress. Large platelets are more active metabolically and enzymatically, and they have increased thrombotic potential in comparison to small platelets. Elevated mean platelet volume and increased platelet count were found to be markers of cardiovascular diseases such as acute coronary syndromes [8] and hypertension [9]. Thus, blood NLR, PLR and MPV are indicators of the overall inflammatory and stress status of the body. Binnetoglu found that both NLR and PLR were predictors of proteinuria in CKD subjects [6] and Taymez revealed that elevated PLR is and independent indicator of erythropoietin resistance in adult patients treated with chronic haemodialysis [25]. Finally, NLR and PLR were found to be associated with all-cause mortality in prevalent HD patients [26]. Our results indicate pathophysiological relation between NLR, PLR and blood pressure also in paediatric patients with chronic kidney disease.

Sunbul et al. found that adult patients with nondipper hypertension had significantly higher NLR and PLR compared to dipper hypertension. Moreover, PLR of more than 107 but not NLR was independent predictor of non-dipper status [5]. Also higher MPV, PLR and NLR were related to nondipping status in hypertensive adult patients with CKD [7]. In our small group of patients we did not find any significant relations between nighttime blood pressure dip and inflammatory indicators.

In our cohort, we have found positive correlations between blood pressure and parathormone, phosphate, and calcium-phosphorus product. In addition, phosphate correlated negatively with nighttime blood pressure dipping. Phosphate is considered nowadays as one of the most lethal uremic toxins with highly negative impact on arterial wall in patients with CKD. Increased phosphataemia and high calcium-phosphorus product lead to medial calcification, known as Mönckeberg's sclerosis. Clinical consequences of medial calcification include increased vascular stiffness, systolic hypertension and left ventricular hypertrophy [27]. Noteworthy, both high-turnover bone disease (with high parathormone levels) and low-turnover bone disease (with low parathormone levels) promote vascular wall calcification. Surprisingly, in our cohort indices of mineral metabolism correlated with diastolic not with systolic blood pressure. Opposite to our results, Vyssoulis et al. in a study of hypertensive adults found positive relation between phosphate concentration and dipping status - highest phosphate status was revealed in "extreme" dippers [28].

Both observational and experimental studies revealed association of vitamin $\mathrm{D}$ with markers of inflammation. Studies in adult patients with CKD suggest link between vitamin D deficiency, degree of inflammation and anaemia and erythropoietin hyporesponsiveness [29], as well as albuminuria [30]. Moreover, paricalcitol, a selective vitamin D receptor activator, was found to reduce hsCRP, tumour necrosis factor-alpha (TNF- $\alpha$ ) and interleukin 6 (IL-6) in CKD adult patients [31]. On the contrary, in our small cross-sectional study we have not found significant relations between vitamin D concentra- 
tion and markers of inflammation (NLR, PLR and MPV).

Ambulatory arterial stiffness index is an ABPMderived marker of arterial compliance [3]. In our cohort we failed to find any significant determinants of AASI, except for elevated lymphocytes. According to literature, arterial stiffness in children with CKD was related to high blood pressure [32], low GFR and low vitamin D status [33]. These differences might be a consequence of small patient number or other, indirect method of evaluation of arterial stiffness, compared to aforementioned studies.

Limitation of our study is small patient sample, which could have precluded disclosure of some relations between ABPM parameters and inflammatory indicators. We also did not evaluate hsCRP or cytokine concentration (e.g. IL-6 or TNF- $\alpha$ ), which are well-established and more precise markers of subclinical inflammation. There is a need for further studies (including prospective trials) on mutual relation between cardiovascular burden and subclinical inflammation in children with chronic kidney disease.

\section{Conclusions}

1. Ambulatory blood pressure monitoring should be used in children with chronic kidney disease on regular basis, especially in those with arterial hypertension.

2. Blood pressure in children with chronic kidney disease may be related to degree of subclinical inflammation.

\section{Conflict of interest}

The authors declare that they have no conflict of interest.

\section{References}

1. Mitsnefes MM. Cardiovascular disease in children with chronic kidney disease. J Am Soc Nephrol. 2012; 23(4): 578-585, doi: 10.1681/ ASN.2011111115, indexed in Pubmed: 22383696.

2. Flynn JT, Daniels SR, Hayman LL, et al. American Heart Association Atherosclerosis, Hypertension and Obesity in Youth Committee of the Council on Cardiovascular Disease in the Young. Update: ambulatory blood pressure monitoring in children and adolescents: a scientific statement from the American Heart Association. Hypertension. 2014; 63(5): 1116-1135, doi: 10.1161/HYP.0000000000000007, indexed in Pubmed: 24591341.

3. Li Y, Wang JG, Dolan E, et al. Ambulatory arterial stiffness index derived from 24-hour ambulatory blood pressure monitoring. Hypertension. 2006; 47(3): 359-364, doi: 10.1161/01. HYP.0000200695.34024.4c, indexed in Pubmed: 16432048.

4. Akchurin OM, Kaskel F. Update on inflammation in chronic kidney disease. Blood Purif. 2015; 39(1-3): 84-92, doi: 10.1159/000368940, indexed in Pubmed: 25662331.
5. Sunbul M, Gerin F, Durmus E, et al. Neutrophil to lymphocyte and platelet to lymphocyte ratio in patients with dipper versus non-dipper hypertension. Clin Exp Hypertens. 2014; 36(4): 217-221, doi: 10 .3109/10641963.2013.804547, indexed in Pubmed: 23786430.

6. Binnetoğlu E, Şengül E, Halhallı $\mathrm{G}$, et al. Is neutrophil lymphocyte ratio an indicator for proteinuria in chronic kidney disease? J Clin Lab Anal. 2014; 28(6): 487-492, doi: 10.1002/jcla.21715, indexed in Pubmed: 24659410.

7. Ahbap E, Sakaci T, Kara E. Serum uric acid levels and inflammatory markers with respect to dipping status: a retrospective analysis of hypertensive patients with or without chronic kidney disease. Clin Exp Hypertens. 2016; 38 (6): 555-563, doi: 10.3109/10641963. 2016.1174251, indexed in Pubmed: 27392197.

8. Endler G, Klimesch A, Sunder-Plassmann H, et al. Mean platelet volume is an independent risk factor for myocardial infarction but not for coronary artery disease. Br J Haematol. 2002; 117(2): 399-404, indexed in Pubmed: 11972524.

9. Nadar SK, Blann AD, Kamath S, et al. Platelet indexes in relation to target organ damage in high-risk hypertensive patients: a substudy of the Anglo-Scandinavian Cardiac Outcomes Trial (ASCOT). J Am Coll Cardiol. 2004; 44(2): 415-422, doi: 10.1016/j. jacc.2004.03.067, indexed in Pubmed: 15261941.

10. Tangvarasittichai S, Pingmuanglaew P, Tangvarasittichai O. Association of Elevated Serum Lipoprotein(a), Inflammation, Oxidative Stress and Chronic Kidney Disease with Hypertension in Non-diabetes Hypertensive Patients. Indian J Clin Biochem. 2016; 31(4): 446-451, doi: 10.1007/s12291-016-0553-1, indexed in Pubmed: 27605742.

11. Kidney Disease: Improving Global Outcomes (KDIGO) CKD Work Group. . KDIGO 2012 Clinical Practice Guideline for the Evaluation and Management of Chronic Kidney Disease. Kidney Int Suppl. 2013; 3(1): 1-150, doi: 10.1038/kisup.2012.73.

12. Schwartz GJ, Muñoz A, Schneider MF, et al. New equations to estimate GFR in children with CKD. J Am Soc Nephrol. 2009; 20(3): 629-637, doi: 10.1681/ASN.2008030287, indexed in Pubmed: 19158356.

13. Kułaga Z, Litwin M, Tkaczyk M, et al. Polish 2010 growth references for school-aged children and adolescents. Eur J Pediatr. 2011; 170(5): 599-609, doi: 10.1007/s00431-010-1329-x, indexed in Pubmed: 20972688

14. Litwin M, Niemirska A, Obrycki Ł, et al. Guidelines of the Pediatric Section of the Polish Society of Hypertension on diagnosis and treatment of arterial hypertension in children and adolescents. Arterial Hypertension. 2018; 22(2): 45-73, doi: 10.5603/ah.2018.0007.

15. Kułaga Z, Litwin M, Grajda A, et al. OLAF Study Group. Oscillometric blood pressure percentiles for Polish normal-weight school-aged children and adolescents. J Hypertens. 2012; 30(10): 1942-1954, doi: 10.1097/HJH.0b013e328356abad, indexed in Pubmed: 22828086.

16. Kidney Disease: Improving Global Outcomes (KDIGO) Anemia Work Group. KDIGO Clinical Practice Guideline for Anemia in Chronic Kidney Disease. Kidney Int Suppl. 2012; 2(4): 288-335, doi: 10.1038/kisup.2012.37.

17. Klaus G, Watson A, Edefonti A, et al. European Pediatric Dialysis Working Group (EPDWG). Prevention and treatment of renal osteodystrophy in children on chronic renal failure: European guidelines. Pediatr Nephrol. 2006; 21(2): 151-159, doi: 10.1007/ s00467-005-2082-7, indexed in Pubmed: 16247644.

18. Rusińska A, Płudowski P, Walczak M, et al. Vitamin D Supplementation Guidelines for General Population and Groups at Risk of Vitamin D Deficiency in Poland - Recommendations of the Polish Society of Pediatric Endocrinology and Diabetes and the Expert Panel With Participation of National Specialist Consultants and Representatives of Scientific Societies-2018 Update. Front Endocrinol (Lausanne). 2018; 9: 246, doi: 10.3389/fendo.2018.00246, indexed in Pubmed: 29904370.

19. Samuels J, Ng D, Flynn JT, et al. Chronic Kidney Disease in Children Study Group. Ambulatory blood pressure patterns in children with chronic kidney disease. Hypertension. 2012; 60(1): 43-50, doi: 10.1161/HYPERTENSIONAHA.111.189266, indexed in Pubmed: 22585950. 
20. Stabouli S, Kotsis V, Toumanidis S. White-coat and masked hypertension in children: association with target-organ damage. Pediatr Nephrol. 2005; 20(8): 1151-1155, doi: 10.1007/s00467-0051979-5, indexed in Pubmed: 15947982.

21. Mitsnefes M, Flynn J, Cohn S, et al. CKiD Study Group. Masked hypertension associates with left ventricular hypertrophy in children with CKD. J Am Soc Nephrol. 2010; 21(1): 137-144, doi: 10.1681/ ASN.2009060609, indexed in Pubmed: 19917781.

22. Mitsnefes MM, Kimball TR, Daniels SR. Office and ambulatory blood pressure elevation in children with chronic renal failure. Pediatr Nephrol. 2003; 18(2): 145-149, doi: 10.1007/s00467-002-1030-z, indexed in Pubmed: 12579404

23. Belsha CW, Wells TG, McNiece KL, et al. Influence of diurnal blood pressure variations on target organ abnormalities in adolescents with mild essential hypertension. Am J Hypertens. 1998; 11(4 Pt 1): 410-417, indexed in Pubmed: 9607378.

24. Tsioufis C, Andrikou I, Thomopoulos C, et al. Comparative prognostic role of nighttime blood pressure and nondipping profile on renal outcomes. Am J Nephrol. 2011; 33(3): 277-288, doi: 10.1159/000324697, indexed in Pubmed: 21372563.

25. Taymez DG, Ucar E, Turkmen K, et al. The predictive value of platelet/lymphocyte ratio in hemodialysis patients with erythropoietin resistance. Ther Apher Dial. 2016; 20(2): 118-121, doi: 10.1111/1744-9987.12380, indexed in Pubmed: 26929254.

26. Yaprak M, Turan MN, Dayanan R, et al. Platelet-to-lymphocyte ratio predicts mortality better than neutrophil-to-lymphocyte ratio in hemodialysis patients. Int Urol Nephrol. 2016; 48(8): 1343-1348, doi: 10.1007/s11255-016-1301-4, indexed in Pubmed: 27118565.
27. Shroff R. Phosphate is a vascular toxin. Pediatr Nephrol. 2013; 28(4): 583-593, doi: $10.1007 / s 00467-012-2347-x$, indexed in Pubmed: 23161206.

28. Vyssoulis G, Karpanou E, Tzamou V, et al. Serum phosphate in whitecoat hypertensive patients: focus on dipping status and metabolic syndrome. Hypertens Res. 2010; 33(8): 825-830, doi: 10.1038/ hr.2010.86, indexed in Pubmed: 20505672.

29. Icardi A, Paoletti E, De Nicola L, et al. Renal anaemia and EPO hyporesponsiveness associated with vitamin D deficiency: the potential role of inflammation. Nephrol Dial Transplant. 2013; 28(7): $1672-$ 1679, doi: 10.1093/ndt/gft021, indexed in Pubmed: 23468534.

30. Isakova T, Gutiérrez OM, Patel NM, et al. Vitamin D deficiency, inflammation, and albuminuria in chronic kidney disease: complex interactions. J Ren Nutr. 2011; 21(4): 295-302, doi: 10.1053/j. jrn.2010.07.002, indexed in Pubmed: 20817560.

31. Donate-Correa J, Domínguez-Pimentel V, Méndez-Pérez ML, et al. Selective vitamin D receptor activation as anti-inflammatory target in chronic kidney disease. Mediators Inflamm. 2014; 2014: 670475, doi: 10.1155/2014/670475, indexed in Pubmed: 24511210.

32. Sinha MD, Keehn L, Milne L, et al. Decreased arterial elasticity in children with nondialysis chronic kidney disease is related to blood pressure and not to glomerular filtration rate. Hypertension. 2015; 66(4): 809-815, doi: 10.1161/HYPERTENSIONAHA.115.05516, indexed in Pubmed: 26259592.

33. Patange AR, Valentini RP, Du W, et al. Vitamin D deficiency and arterial wall stiffness in children with chronic kidney disease. Pediatr Cardiol. 2012; 33(1): 122-128, doi: 10.1007/s00246-011-0101-y, indexed in Pubmed: 21912948. 